\title{
TO ASSESS THE ROLE OF LINGUAL FLAP FOR THE REMOVAL OF LOWER WISDOM TOOTH.
}

1. BDS, MSc (OMFS)

Institute of Dentistry, LUMHS Jamshoro.

2. BDS, MSc

Assistant Professor Orthodontics Bibi Aseefa Dental College Larkana.

3. BDS, MCPS

Assistant Professor Oral Medicine Liaquat College of Medicine \& Dentistry

4. BDS, FFDRCS (Ireland)

Professor

Oral \& Maxillofacial Surgery LUMHS, Jamshoro.

5. BDS, MSc (OMFS) Ph.D Scholar (Oral Pathology)

Institute of Dentistry, LUMHS, Jamshoro.

Correspondence Address: Prof. Syed Ghazanfar Hassan Department of Oral \& Maxillofacial Surgery

LUMHS, Jamshoro.

chairman_oral@hotmail.com

Article received on:

28/11/2019

Accepted for publication

07/02/2020
Noman Ahmed ${ }^{1}$, Almas Rahoojo ${ }^{2}$, Syed Zafar Abbas ${ }^{3}$, Syed Ghazanfar Hassan ${ }^{4}$, Zunair Memon ${ }^{5}$

ABSTRACT... Objectives: To assess the role of lingual flap in encountering lingual nerve injury during the surgical elimination of lower wisdom tooth. Study Design: Cross Sectional Case Control study. Setting: Department of Oral \& Maxillofacial Surgery, Institute of Dentistry, Liaquat University of Medical \& Health Sciences Jamshoro / Hyderabad. Period: January 2016 to September 2016. Material \& Methods: Subjects were categorized into two categories: Group-A (lingual flap) \& group-B (control group) each having 52 patients by Lottery method. In group $A$ an envelope mucoperiosteal flap followed by lingual flap elevation carried out and in group B only envelope flap was carried out. All patients were reviewed on the first postoperative day and again 1 and $3^{\text {rd }}$ week after surgery. At each postoperative visit, patient was examined for sensory nerve impairment of the lingual nerve by same observer. Results: Total 104 cases were studied, all the cases categorized among two groups 52 in each group. In group-A 34 were males and 18 were females, while in group-B 44 were male and 8 were females. There was no significant difference among both groups according to the pre-operative assessment. According to objective findings, lingual nerve paresthesia was found among 2 cases of group A on $1^{\text {st }}$ visit, while no any case was found with nerve injury in group B. Out of 2 cases, one case was improved and only one had presented with complain at $2^{\text {nd }}$ visit and $3^{\text {rd }}$ visit, no significant difference among both groups, $\mathrm{p}$-values were quite insignificant. Conclusion: It was concluded that lingual nerve injury (LNI) occurred among few cases of lingual flap group which was insignificantly higher as compare to control group, but the nature of injury was temporary.

Key words: Impacted Mandibular Third Molar, Impairment, Lingual Flap, Nerve Injury, Sensory.

Article Citation: Ahmed N, Rahoojo A, Abbas SZ, Hassan SG, Memon Z. To assess the role of lingual flap for the removal of lower wisdom tooth. Professional Med J 2020; 27(8):1656-1663. DOI: 10.29309/TPMJ/2020.27.08.4424

\section{INTRODUCTION}

Impacted tooth is one that fall short to erupt into its proper functional occlusion at the age of eruption. ${ }^{1}$ Mandibular third molar can cause pain, pericoronitis, periodontal defects, caries, cyst, odontogenic tumor and neurogenic pain. ${ }^{2,3}$ The position of an impacted third molar is categorized radio graphically using Winter's (Angulation) Classification based on the inclination of the impacted wisdom tooth (3rd molar) to the long axis of the $2^{\text {nd }}$ molar i.e. Mesioangular, Distoangular, Vertical or Horizontal impaction. ${ }^{1}$ The surgical removal of impacted mandibular third molar is one of the most frequent procedures performed by Oral \& Maxillofacial Surgeon. ${ }^{1}$

The surgical removal of impacted $3^{\text {rd }}$ molar can vary in difficulty, degree of trauma to the surgical site and sometimes it requires bone removal and soft tissue injury which usually causes significant postoperative pain, swelling and trismus \& nerve injury. ${ }^{2,3}$

Many clinical studies are performed to reduce postoperative complications by using corticosteroids, well planned atraumatic surgery, flap design, muscle relaxant and Non-steroidal anti-inflammatory drugs. ${ }^{4}$

There are various direct and indirect factors which have the capability to influence the risk of lingual nerve injury. Methods which are directly involved in causing injury to the nerve are: local anesthetic technique, pattern of incision 
and designing of flap, technique of lingual flap reflection and retraction, removal of distal bone, lingual bone split, tooth separation and suturing method. Factors that causes increase in difficulty of surgery or render the nerve susceptible to injury are the indirect factors. Anatomy of lingual nerve, anesthetic form, eruption state, angulation and deepness of the lower third molar and the understanding of the surgeon in dealing with third molar are the mostly involved indirect factors. ${ }^{5}$

Numbness of the lower lip, chin and tongue are the documented complications of inferior alveolar and lingual nerve damage. Despite improvement in the preoperative assessment of impacted lower wisdom teeth and techniques of removal; inferior alveolar and lingual nerve damage remains a significant factor during 3rd molar surgery which has serious medical and legal implications. In previous studies, the prevalence of damage to the lingual nerve varied from almost $0 \%$ to $23 \%$. This may involve temporary or permanent lingual sensory disturbances.The incidence of temporary deficit is between $0-23 \%$ and permanent $0-8 \%$, compared with temporary $(0.4$ to $8.4 \%){ }^{6}$

Lingual flap retraction occasionally leads to lingual nerve injury. The mechanism by which this type of injury occurs is still question to be answered on various grounds, but the most involved theory or causes includes are perforation of lingual plate while surgery, trauma or harm to lingual nerve while sectioning of tooth or ostectomy, tradition of using lingual flap retractor and procedure performed with chisel by lingual approach. ${ }^{7}$

The approach which is usually safe to perform third molar surgery is buccal. Alternate or other technique that has gained popularity is lingual flap retraction. With this technique the lingual nerve can be kept out of surgical field by gentle retraction. The benefit of lingual flap reflection is that nerve is recognized and sheltered away from the surgical ground. ${ }^{8}$

Because of its anatomic position, the lingual nerve may be injured during third molar surgery, causing temporary or permanent neurosensory disability, loss of sensory function, and neurogenic symptoms. Temporary injury occurs in as many as $15 \%$ of cases and permanent injury in $0.3 \%$ to 0 . $\%$ of cases. These are "closed injuries," meaning that the surgeon is unaware of the problem at surgery and often cannot diagnose the origin of the injury or classify it appropriately. ${ }^{9}$

This sensory instability can be bothersome as it causes troubles with verbal communication and mastication and may unfavorably change the patient's quality of living. They also constitute as one of the most frequent causes of complaints and litigation. ${ }^{10}$

\section{RATIONALE}

Many clinicians prefer a more invasive approach to perform lingual flap due to ease in access and instrumentation while many clinicians fear the consequences of such approach and avoid releasing the lingual periosteum to reduce incidence of lingual nerve injury, hence the aim of this study is incidence of lingual nerve injury during $3^{\text {rd }}$ molar surgery by comparing lingual flap and without lingual flap on postoperative follow up.

\section{MATERIAL \& METHODS}

This Cross sectional case control study with convenience sampling method was conducted at Department of Oral \& Maxillofacial Surgery, Institute of Dentistry, and Liaquat University of Medical \& Health Sciences Jamshoro / Hyderabad.

As lingual nerve damage was stated $5 \%{ }^{6}$ A sample size was calculated using openepi.com with having confidence interval of 95\%, margin of error $5 \%$. The sample size stands to be $n=104$ (10\% non-respondents).

\section{Group-A}

LINGUAL FLAP (52 patients).

\section{Group-B}

CONTROL (52patients).

\section{Inclusion Criteria}

- Patient having impacted mandibular third molar. 
- Patient aged $\geq 18$ and $\leq 40$ years irrespective of gender.

- Patient willing to partake in this study.

- Mesioangular

\section{Exclusion Criteria}

- Patient having neurological disorders.

- Smokers and poor oral hygiene.

- Patient having any systemic diseases.

- Patients having any pathological lesion in the area of impacted tooth.

The impacted wisdom teeth was diagnosed by clinical examination and radiographs like OPG and periapical radiographs. The demographic and clinical parameters like gender, age, preoperative assessment of light touch, tactile discrimination, pain awareness \& moving two point discrimination were recorded using questionnaire. ${ }^{3}$ Subjects were categorized into two categories Group-A (lingual flap) \& group-B (control group) each having 52 patients by Lottery method.

All surgical extractions were done under local anesthesia by giving conventional inferior alveolar nerve block. Also anesthetizing lingual nerve and long buccal nerve by xylocaine $2 \%$ with epinephrine 1:100000 (Medicaine Hunos, Co, Ltd Korea). In group A an envelope mucoperiosteal flap followed by lingual flap carried out and in group B only envelope flap was given. After the elimination of tooth any sharp bone was smoothened by bone filer and the socket was washed with $0.9 \%$ normal saline, then suturing was done with vicryl 3-0 (Johnson and Johnson made in USA) in both groups.

All subjects were appraised on the 1st postoperative day, 1 week following surgical procedure and after $3^{\text {rd }}$ Week. At each postoperative visit, each patient was examined for sensory nerve impairment of the lingual nerve via same observer.

Regarding sensory nerve assessment of the lingual nerve, each patient was asked if he or she had any tingling or numbness of the tongue. The presence or absence of sensory impairment of the lingual nerve was confirmed via a further objective assessment of nerve injury which was carried out according to the methods described via Ferdousi and McGregor and practiced via Mason and Blackburn which were as follows:

Moving two-point discrimination: The blunt tips of a tweezers were moved on the dorsum of the tongue on each side from posterior to anterior. The procedure was repeated while decreasing the distance between the two tips of the tweezers until the patient could sense them as one point rather compared to two. The sensibility of the tongue at the operated side was compared to that on the contralateral side.

\section{RESULTS}

In group A 34 were males and 18 were female, while in group b 44 were male and 8 were female. Statistically male were significantly more in contrast to and female in group $B$ as compare to group A, p-value 0.024. Table-l.

There was no significant difference among both groups according to the pre-operative assessment, when patients were interviewed regarding feeling of finger with tongue, affected sense of taste, temperature of food, feeling of tongue regarding teeth, accidental bite on tongue, tingling of tongue and affected speech. P-values were quite insignificant, results showed in Table-II.

According to $1^{\text {st }}$ postoperative follow-up assessment when patients were interviewed, rate of feeling of finger with tongue, temperature of food, feeling of tongue regarding teeth was higher in group $B$, and affected sense of taste, tingling of tongue were higher in group $A$, while there was no significant difference according to accidental bite on tongue and among both groups, results showed in Table-III.

According to $2^{\text {nd }}$ postoperative follow-up assessment when patients were interviewed, the rate of feeling of finger with tongue, affected sense of taste, temperature of food was higher in group $B$, and tingling of tongue was higher in group $A$, while there was no significant difference according to speech among both groups, results showed in Table-IV. 
According to $3^{\text {rd }}$ postoperative follow-up assessment when patients were interviewed, there was no significant difference according to feeling of finger with tongue, affected sense of taste, temperature of food, feeling of tongue regarding teeth, accidental bite on tongue, tingling of tongue among both groups, results showed in Table-V.
According to objective findings, there was nerve was found among 2 cases of group A on $1^{\text {st }}$ visit, while no any cases was found with nerve injury in group B. Out of 2 cases one cases was improved and only one had presented with complain at $2^{\text {nd }}$ visit and $3^{\text {rd }}$ visit, no significant difference among both groups, $p$-values were quite insignificant, results showed in Table-Vl.

\begin{tabular}{|l|c|c|c|}
\hline \multirow{2}{*}{ Gender } & \multicolumn{2}{|c|}{ Group } & Total \\
\cline { 2 - 4 } & A & B & 78 \\
\hline Male & 34 & 44 & 2 \\
\hline Female & 18 & 8 & 104 \\
\hline Total & 52 & 52 & 0.024 \\
\hline
\end{tabular}

Table-I. Patient distribution according to gender $n=104$.

\section{Preoperative Assessment}

Group

A
B

Total

P-Value

Q1. If you touch your tongue with your finger, can you feel your finger with your tongue?

\begin{tabular}{|l|c|c|c|c|}
\hline Yes & 52 & 52 & 104 & 1.00 \\
\hline No & 0 & 0 & 0 & \\
\hline Q2. Is your sense of taste affected? & & & \\
\hline
\end{tabular}

\begin{tabular}{|l|c|c|c|c|}
\hline Yes & 0 & 0 & 0 & 1.00 \\
\hline No & 52 & 52 & 104 & \\
\hline
\end{tabular}

Q3. Can you tell the temperature of food and drink on that side of mouth?

\begin{tabular}{|l|c|c|c|c|}
\hline Yes & 52 & 52 & 104 & 1.00 \\
\hline No & 0 & 0 & 0 & \\
\hline
\end{tabular}

Q4. If you rub your tongue, over your teeth, can you tell if they are clean or dirty?

\begin{tabular}{|l|c|c|c|c|}
\hline Yes & 50 & 52 & 102 & 1.00 \\
\hline No & 2 & 0 & 2 & \\
\hline
\end{tabular}

Q5. Do you bite your tongue by accident?

\begin{tabular}{|l|c|c|c|c|}
\hline Yes & 2 & 0 & 2 & 0.153 \\
\hline No & 50 & 52 & 102 & \\
\hline
\end{tabular}

Q6. Do you have any tingling of your tongue?

\begin{tabular}{|l|c|c|c|c|}
\hline Yes & 0 & 0 & 0 & 1.00 \\
\hline No & 52 & 52 & 104 & \\
\hline
\end{tabular}

Q7. Is your speech affected?

\begin{tabular}{|l|c|c|c|c|}
\hline Yes & 0 & 0 & 0 & 1.00 \\
\hline No & 52 & 52 & 104 & \\
\hline
\end{tabular}

Table-II. Patient distribution according to according to preoperative assessment $n=104$. 


\section{\begin{tabular}{ll|l|l} 
& Group & Total & P-Value
\end{tabular}}

Q1. If you touch your tongue with your finger, can you feel your finger with your tongue?

\begin{tabular}{|c|c|c|c|c|}
\hline Yes & 45 & 52 & 97 & \multirow{2}{*}{0.00} \\
\hline No & 7 & 0 & 7 & \\
\hline \multicolumn{5}{|c|}{ Q2. Is your sense of taste affected? } \\
\hline No & 48 & 52 & 100 & 0.041 \\
\hline \multicolumn{5}{|c|}{ Q3. Can you tell the temperature of food and drink on that side of mouth? } \\
\hline Yes & 48 & 52 & 100 & 0.041 \\
\hline \multicolumn{5}{|c|}{ Q4. If you rub your tongue, over your teeth, can you tell if they are clean or dirty? } \\
\hline Yes & 4 & 52 & 98 & \multirow{2}{*}{0.012} \\
\hline No & & 0 & & \\
\hline \multicolumn{5}{|c|}{ Q5. Do you bite your tongue via accident? } \\
\hline Yes & 2 & 0 & 2 & 0.153 \\
\hline No & 45 & 52 & 97 & 0.00 \\
\hline \multicolumn{5}{|c|}{ Q7. Is your speech affected? } \\
\hline Yes & 1 & 0 & 1 & \multirow{2}{*}{0.315} \\
\hline No & 51 & 52 & 103 & \\
\hline
\end{tabular}

Table-III. Patient distribution according to $1^{\text {st }}$ postoperative follow-up assessment $n=104$.

\section{$2^{\text {nd }}$ Postoperative Follow-up Assessment \\ Group \\ A B \\ Total \\ P-Value}

Q1. If you touch your tongue with your finger, can you feel your finger with your tongue?

Yes

No

49

3

2

50

No

Q3. Can you tell the temperature of food and drink on that side of mouth?

Yes

No

50

2

50

Q4. Yes

No

Q5. Do you bite your tongue via accident?

Yes

No

48

4

\begin{tabular}{|c|c}
\hline 8 \\
\hline
\end{tabular}

52

0

1

51

0

0

0

52

\begin{tabular}{|c|c|}
\hline 0 & 4 \\
\hline 52 & 100 \\
\hline
\end{tabular}

\section{1}

103

101

3

0.079

Q6. Do you have any tingling of your tongue?

Yes

No

48

0

52

0
104

104

\begin{abstract}
Yes
\end{abstract}
No

52

52

Table-IV. Patient distribution according to $2^{\text {nd }}$ postoperative follow-up assessment $n=104$. 


\section{\begin{tabular}{l|l}
$3^{\text {rd }}$ Postoperative Follow-up Assessment & Group \\
\hline
\end{tabular}}

A
B
Total

P-Value

Q1. If you touch your tongue with your finger, can you feel your finger with your tongue?

\begin{tabular}{|l|c|c|c|c|}
\hline Yes & 51 & 52 & 103 & 0.315 \\
\hline No & 1 & 0 & 1 & 1 \\
\hline
\end{tabular}

Q2. Is your sense of taste affected?

Yes

No

01

51

10

\begin{tabular}{|r|r}
\hline 0 & 1 \\
\hline 52 & 103 \\
\hline
\end{tabular}

0.315

Q3. Can you tell the temperature of food and drink on that side of mouth?

\begin{tabular}{|l|c|c|c|c|}
\hline Yes & 51 & 52 & 103 & 0.315 \\
\hline No & 1 & 0 & 1 & \multirow{2}{*}{ No } \\
\cline { 1 - 3 }
\end{tabular}

Q4. If you rub your tongue, over your teeth, can you tell if they are clean or dirty?

\begin{tabular}{|l|c|c|c|c|}
\hline Yes & 51 & 52 & 103 & 0.315 \\
\hline No & 1 & 0 & 1 & 0.35 \\
\hline
\end{tabular}

Q5. Do you bite your tongue via accident?

Yes

No

01

51

0

52

01

103

1.00

Q6. Do you have any tingling of your tongue?

\begin{tabular}{|l|c|c|c|c|}
\hline Yes & 02 & 0 & 02 & 0.153 \\
\hline No & 50 & 52 & 102 & 02 \\
\hline
\end{tabular}

Q7. Is your speech affected?

\begin{tabular}{|l|c|c|c|c|}
\hline Yes & 0 & 0 & 0 & 1.00 \\
\hline No & 52 & 52 & 104 & \\
\hline
\end{tabular}

Table-V. Patient distribution according to $3^{\text {rd }}$ postoperative follow-up assessment $n=104$.

\section{Objective Findings of Nerve Injury}

Obj. $1^{\text {st }}$ Moving two-point discrimination:

The blunt tip of a tweezers is moved on the dorsum of the tongue on each side from posterior to anterior. The procedure is repeated while decreasing the distance between the two tips of the tweezers until the patient can sense them as one point rather compared to two.

Obj.2 $2^{\text {st }}$ Moving two-point discrimination:

The blunt tip of a tweezers is moved on the dorsum of the tongue on each side from posterior to anterior. The procedure is repeated while decreasing the distance between the two tips of the tweezers until the patient can sense them as one point rather compared to two.

Obj.3. $3^{\text {st }}$ Moving two-point discrimination:

The blunt tip of a tweezers is moved on the dorsum of the tongue on each side from posterior to anterior. The procedure is repeated while decreasing the distance between the two tips of the tweezers until the patient can sense them as one point rather compared to two.

\begin{tabular}{|c|c|c|c|c|}
\hline & \multicolumn{2}{|c|}{ Group } & \multirow[t]{2}{*}{ Total } & \multirow[t]{2}{*}{ P-Value } \\
\hline & A & B & & \\
\hline Yes & 49 & 52 & 101 & \multirow{2}{*}{0.79} \\
\hline No & 03 & 0 & 3 & \\
\hline Yes & 51 & 52 & 103 & \multirow{2}{*}{0.315} \\
\hline No & 01 & 0 & 01 & \\
\hline Yes & 51 & 52 & 103 & \multirow{2}{*}{0.315} \\
\hline No & 01 & 0 & 01 & \\
\hline
\end{tabular}

Table-VI. Patient distribution according to objective findings of nerve injury $n=104$.

\section{DISCUSSION}

Though the raising of lingual flap and placement of retractor can cause traction injury to the nerve which will resolve within few weeks after procedure but it protects the nerve from irreversible damage from drills, instruments or lingual plate or tooth fracture. ${ }^{11}$ These findings of literature are associated with findings of this study.

In this study out of 104 cases, 52 in each group, statistically male were significantly further and female were lower in group B as compare to 
group $A, p$-value 0.024 . Similar findings seen in the study of Shuja RA et $\mathrm{al}^{12}$, regarding age and gender. Koyuncubö et $\mathrm{al}^{13}$ documented that patients reported were 29 females and 7 males.

In this study there was nerve injury found among 2 cases of group A (lingual flap) on $1^{\text {st }}$ visit, while no any cases was found with nerve injury in group B. Out of 2 cases one case was improved and only one had presented with complain at $2^{\text {nd }}$ visit and $3^{\text {rd }}$ visit, no significant difference among both groups, p-values were quite insignificant. Similarly Gomes $\mathrm{AC}$ et $\mathrm{al}^{14}$ documented that lingual nerve damage occurred in $9.1 \%$ in the experimental group in which lingual flap retraction was carried out. In the control group, damage to the lingual nerve was not observed. In the favor of this study other documented that in most cases, the nerve heals spontaneously but permanent damage has been described in around $0.5 \%$ of the patients. ${ }^{15}$ Injury to lingual nerve raises serious therapeutic and legal issues. The exact mechanism of injury is still controversial but commonest causes are perforation of lingual plate, reflection and retraction of lingual flap, trauma to lingual flap during bone removal and tooth sectioning. Supracrestal incision can possibly result in damage as nerve can be located in this region in a few cases and can possibly get sectioned. ${ }^{1}$

Pogrel MA and Goldman KE et $\mathrm{al}^{17}$ eliminated mandibular wisdom teeth of 250 patients in Oral and Maxillofacial Surgical procedure Clinic at the University of California, San Francisco, they reflected and retracted lingual flap with specially designed lingual retractor in all those patients in which distal bone removal or tooth sectioning was anticipated, the findings showed transient lingual nerve paraesthesia in $1 . \%$ of cases and $0 \%$ permanent lingual nerve damage. The results of our study show that the incidence of nerve damage was very less only among 2 cases when lingual flap was reflected and retracted via a periosteal elevator. So results are inconsistent with those who report higher chances of lingual nerve associated with reflection and retraction of the nerve, but we have found this injury to be temporary.
Conversely, studies of Gomes et $\mathrm{al}^{18}$ and GargalloAlbiol et $\mathrm{al}^{19}$ showed that a significant elevation in incidence of lingual nerve damage was found when a lingual flap was retracted and reflected. In addition to these two methods for removal of third molar, Rud et $\mathrm{al}^{20}$ and Yeh et $\mathrm{al}^{21}$ advocated the lingual split method where lingual cortex is deliberately fractured to protect the lingual nerve. But this method was documented to be associated with elevated incidence of lingual nerve damage via Pichler et al. ${ }^{22}$ In present study lingual plate was preserved in all cases. Shad S et $\mathrm{al}^{51}$ documented that lingual nerve damage occurred in $8.94 \%$ in Group A in which lingual flap retraction was carried out but damage was reversible. In group B, 2. 3\% lingual nerve damage was observed and nature of damage was permanent.

\section{CONCLUSION}

It was concluded that lingual nerve injury occurred among few cases of lingual flaps retraction group which was insignificantly higher as compare to control method, but the nature of injury was temporary. Lingual retraction for third molar removal improves access to the surgical site and can simplify third molar removal. Further research needed to assess the importance of lingual flap method.

There is no any conflict of interest in this study. As all the instruments and material used in this study are available at Liaquat University Hospital Hyderabad/Jamshoro.

Copyright $(07$ Feb, 2020.

\section{REFERENCES}

1. Punjabi SK, Khoso NA, Butt AM, Channar KA. Third molar impaction: Evaluation of the symptoms and pattern of impaction of mandibular third molar teeth. J LUMHS 2013; 12(01):2.

2. Ali R, Shaikh T, Memon M, Shams S. Efficacy of intra-masseteric and submucosal dexamethasone injection in surgical extraction of impacted lower third molar. Professional Med J 2019; 2 (7):1141-114.

3. Ehsan A, Bukhari SA, Ashar AM, Junaid M. Effects of pre-operative submucosal dexamethasone injection on the postoperative swelling and trismus following surgical extraction of mandibular third molar. $\mathrm{J}$ Coll Physicians Surg Pak. 2014; 24(7):489-92. 
4. de Sousa Santos JA, da Silva LC, de Santana Santos $\mathrm{T}$, Júnior LR, et all. Comparative study of tramadol combined with dexamethasone and diclofenac sodium in third-molar surgery. $\mathrm{J}$ Cranio Maxillofac Surg. 2012; 40(8): 94-700.

5. Bataineh $A B$, Ra'ad $A B$. The effect of modified surgical flap design for removal of lower third molars on lingual nerve injury. J Clin oral investi. 2017; 21:20919.

6. Khan A, Zaman $\mathrm{H}$, Aziz H. Frequency of Lingual nerve injury during mandibular 3rd molar extraction under local anesthesia. Ann Pak Inst Med Sci. 201:4-7.

7. Pippi R, Spota A. Prevention of lingual nerve injury in third molar surgery: Literature Review J Oral Maxillofac Surg 2017; 75:890-900.

8. Shad S, Shah SM, Alamgir A, Abbasi MM. Frequency of lingual nerve injury in mandibular third molar extraction: A comparison of two surgical techniques. J Ayub Med Coll Abbottabad. 2015; 27(3):580-3.

9. Hillerup S, Stoltze K. Lingual nerve injury in third molar surgery: I. Observations on recovery of sensation with spontaneous healing. Int J Oral Maxillofac Surg. 2007; 3 (10):884-9.

10. Meshram VS, Meshram PV, Lambade P. Assessment of nerve injuries after surgical removal of mandibular third molar: A prospective study. Asian Journal of Neuroscience Volume 2013,

11. Pichler JW, Beirne OR. Lingual flap retraction and prevention of lingual nerve damage correlated with third molar surgery: A systematic review of the literature. Oral Surg Oral Med Oral Pathol Oral Radiol Endod 2001; 91(4):395-401.

12. Shuja RA. Lingual nerve damage during wisdom teeth surgery. Pakistan Oral \& Dent. Jr. 2002; 22(2);4-9.
13. Koyuncubö, Zeytinoğlu M, Cetingül E. Comparison of two different flap methods in the surgical elimination of bilateral impacted mandibular wisdom teeth. Turkish Journal of Medical Sciences. 2013; 43( ):891-8.

14. Gomes AC, Silva ED, da Silva LC. Lingual nerve damage after mandibular third molar surgery: A randomized clinical trial. Journal of oral and maxillofacial surgery. 2005; 3(10):1443-.

15. Blackburn CW, Bramley PA. Lingual nerve damage correlated with elimination of lower wisdom teeth. $\mathrm{Br}$ Dent J 1989; 1 7(3):103-7.

16. Pogrel MA, Le $H$. Etiology of lingual nerve injuries in third molar region: A cadaver and histologic study. J Oral Maxillofac Surg 200; 4(12):1790-4.

17. Pogrel MA, Goldman KE. Lingual flap retraction for third molar elimination. J Oral Maxillofac Surg 2004; 2(9):1125-30.

18. Gomes AC, Vasconcelos BC, de Oliveira e silva ED, de Silva LC. Lingual nerve damage after mandibular third molar surgery: A randomized clinical trial. J Oral Maxillofac Surg 2005; 3(10):1443.

19. Gargallo-Albiol J, Buenechea-Imaz R, Gay-Escodo C. Lingual nerve protection during surgical elimination of lower wisdom teeth. A prospective randomized study. Int J Oral Maxillofac Surg 2000; 29(4):2 8-71.

20. Rud J. Reevaluation of lingual split bone method for elimination of impacted mandibular wisdom teeth. $J$ Oral Maxillofac Surg 1994; 42(2):114-7.

21. Yeh CJ: Simplified split bone method for elimination of impacted wisdom teeth. Int J Oral Maxillofac Surg 1995; 24(5):348-50.

22. Pichler JW, Beirne OR. Lingual flap retraction and prevention of lingual nerve damage correlated with third molar surgery: A systematic review of the literature. Oral Surg Oral Med Oral Pathol Oral Radiol Endod 2001; 91(4):395-401.

\begin{tabular}{|c|c|c|c|}
\hline \multicolumn{4}{|c|}{ AUTHORSHIP AND CONTRIBUTION DECLARATION } \\
\hline Sr. \# & Author(s) Full Name & Contribution to the paper & Author(s) Signature \\
\hline 1 & Noman Ahmed & $\begin{array}{l}\text { Principal Author, Data } \\
\text { collection. }\end{array}$ & \\
\hline 2 & Almas Rahoojo & Discussion. & Almans \\
\hline 3 & Syed Zafar Abbas & Manuscript designing. & \\
\hline 4 & Syed Ghazanfar Hassan & References, Proof read. & \\
\hline 5 & Zunair Memon & Results. & \\
\hline
\end{tabular}

